\title{
PEMBELAJARAN ORGANISASI MAKHLUK HIDUP BERBASIS GAMIFICATION MENGGUNAKAN MOBILE AUGMENTED REALITY
}

\author{
Didik Wahyu Hidayat, Dedi Kuswandi, dan Saida Ulfa \\ Universitas Negeri Malang \\ e-mail: didikwahyu10@gmail.com
}

\begin{abstract}
ABSTRAK: Pembelajaran biologi dengan bab organisasi makhluk hidup pada umumnya menggunakan pola klasikal dengan metode ceramah dan menggunakan LCD proyektor dalam menyampaikan materi. Sehingga diperlukan inovasi pembelajaran agar ada peningkatan proses dan hasil belajar para pebelajar secara menyenangkan. Salah satu upayanya adalah dengan mengembangkan prototype model pembelajaran individual berbasis gamification menggunakan mobile augmented reality. Dengan menggunakan model pengembangan ASSURE, hasil pengujian terhadap prototype membuktikan adanya peningkatan perhatian individu para pebelajar terhadap materi biologi dan para pebelajar mampu belajar secara individu secara efektif, efisien dan menyenangkan.
\end{abstract}

Kata Kunci: organisasi makhluk hidup, gamifcation, mobile augmented reality

\section{PENDAHULUAN}

Pembelajaran di kelas pada umumnya pembelajar memberi informasi pengetahuan sementara pebelajar menerima yang artinya guru besifat aktif sementara pebelajar bersifat aktif. Salah satu contohnya terjadi di sekolah SMPN 13 Malang. Berdasarkan hasil wawancara bersama guru biologi (IPA) pada pembelajaran IPA dalam praktiknya masih menggunakan pembelajaran klasikal, karena model klasikal dianggap mampu memenuhi kebutuhan baik keseluruhan pebelajar maupun secara perseorangan.

Menurut Yuliati

(2008:6)

"pendidikan IPA diarahkan pada inkuiri dan berbuat sehingga dapat membantu pebelajar untuk memperoleh pemahaman lebih mendalam tentang alam sekitar". Berdasarkan hal tersebut pembelajaran IPA khususnya pebelajar tidak hanya pasif melainkan aktif berbuat Ata lebih memahami konten IPA.

Salah satu strategi dalam mewujudkannya bagaimana pebelajar aktif berbuat yakni dengan gamification. Menurut Lee dan Hammer (2011) bahwa pengertian dari gamification adalah belajar dengan bermain layaknya games yaitu terdapat misi yang harus diselesaikan oleh pebelajar dan setiap menyelesaikan tugas pada misi tersebut pebelajar dapat sebuah poin. Gamification yang menurut Karl dalam Olsson, Mozelius \& Collin (2015) "to gain a person's attention and to involve him or her in the process you have created." Perlunya media yang meningkatkan pebelajar sebagai proses penunjang agar tercipta proses pembelajaran dapat terlaksana.

Kombinasi dari perkembangan teknologi yang ada dengan teknologi yang baru sehingga muncul inovasi. Hal ini berimplikasi pada inovasi pada sebuah media pembelajaran. Media pembelajaran hasil kombinasi teknologi cetak dan mobile device contohnya tablet dan smartphone didalamnya terdapat augmented reality. Salah satu contohnya dengan membuat mobile device augmented reality dan poster bab sistem organisasi kehidupan. Kombinasi mobile device augmented reality dan poster dianggap mampu memberikan inovasi dalam pembelajaran kla-sikal. Hal yang mendasari pemilihan mobile device adalah 
bahwa menurut Molenda dan Boling (2008: 98) menjelaskan bahwa "like web-based resources, mobile resources may be used primarily for performance support and to supplement traditional delivery in a new hybrid mode ". Sementara Jason Hag dalam Joan (2015:9) "augmented reality is uniquely changing the way people learn with mobile device".

Mobile device augmented reality, lembar pengamatan dan poster dikombinasikan dengan metode observasi dirancang mampu meningkatkan keaktifan individual pebelajar dan disesuaikan kurikulum di sekolah tersebut. Poster memiliki keunggulan yang menurut Sadiman, Rahardjo, Haryono, dan Rahardjito (2012) menyatakan "poster tidak saja penting untuk menyampaikan kesan-kesan tertentu tetapi dia mampu pula untuk mempengaruhi dan memotivasi tingkah laku orang yang melihatnya." Oleh karena itu, diharapkan pembelajaran mengenai sistem organisasi kehidupan lebih meningkatkan perhatian karena dalam penyajiannya konten dalam bentuk 3 dimensi yang menyajikan pengetahuan berupa fakta guna mencapai tujuan yang diinginkan oleh pembelajar.

\section{Metode}

Metode yang digunakan dalam mengembangkan prototype pembelajaran ASSURE terdapat beberapa tahap pelaksanaan yang disajikan dalam bagan dibawah ini:

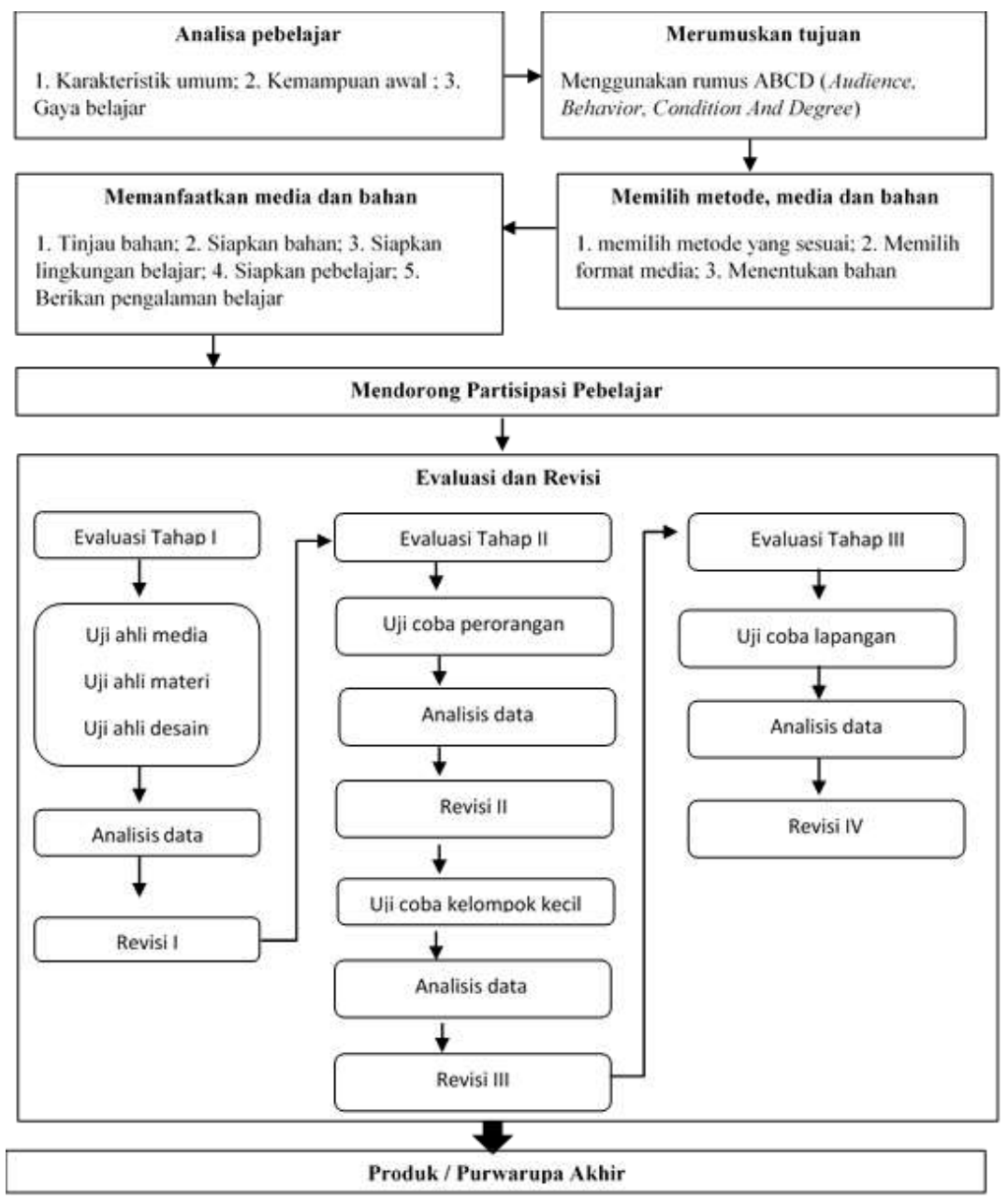

Gambar 2.1 Rancangan Penelitian Pengembangan

\section{Analyze Learners (Analisis Pebelajar)}

Tujuan utama para pembelajar yaitu bagaimana dapat memenuhi setiap 
kebutuhan unik dari setiap pebelajar sehingga dapat mencapai tingkat belajar yang maksimum maka hal pertama yang harus dilakukan yaitu menganalisis karakter pebelajar SMPN 13 Malang kelas 7. Faktor - faktor kunci dalam menganalisis karakter anak dalam Model ASSURE ini terbagi atas 3 yaitu

a) Karakteristik Umum: Pada tahap ini yaitu karakteristik yang dilihat adalah karakteristik pebelajar SMPN 13 Malang yakni era digital native memungkinkan penggunaan smartphone dalam pembelajaran, para pebelajar yang mayoritas kesehariannya menggunakan gadget melalui koneksi Internet dalam mencari informasi atau pengetahuan jika tidak diwadahi dengan pembelajaran yang terarah akan sia-sia. Untuk itu perlunya penggunaan media smartphone dalam penyampaian materi pembelajaran.

b) Kemampuan awal ( Kompetensi dasar spesifik): Kemampuan awal atau keterampilan prasyarat dalam memahami materi tentang organisasi makhluk hidup sudah mereka kenali sejak materi sebelumnya, yakni memahami klasifikasi makhluk hidup. Selain itu, penggunaan gadget (smartphone) juga sudah dapat mengoperasikannya.

c) Gaya belajar: Gaya belajar dari masing-masing pebelajar di SMPN 13 Malang sangat beragam. Terdapat 3 gaya belajar yang ada di kelas 7 yakni auditori, visual, dan kinestetik. Untuk itu diperlukan media yang juga dapat mewadahi ketiga gaya belajar dari masing-masing pebelajar yang ada di kelas.

\section{States Objectives (Merumuskan Tujuan)}

Langkah kedua dalam model ASSURE ini yaitu merumuskan tujuan umum dan tujuan khusus pembelajaran yang ingin dicapai. Tujuan khusus pembelajaran dibuat berdasarkan kriteria sebagai berikut: 1) mengacu pada tujuan umum pembe-lajaran; 2) jelas dan berdasarkan perilaku yang dapat diamati; 3 ) dapat diukur; 4) dirumuskan secara spesifik 5) menggambarkan adanya empat komponen yaitu ABCD (Audience, Behavior, Condition, Degree).

Tujuan umum Mengenal Bagian Makhluk Hidup, adapun tujuan khusu diantarnya, 1) Pebelajar dapat mengenal bentuk sel dan organ melalui contoh model 3 dimensi augmented reality. 2) Pebelajar dapat mengenal macam-macam sel dan organ melalui contoh model 3 dimensi augmented reality. 3) Pebelajar dapat menjelaskan macam-macam sel dan organ melalui contoh model 3 dimensi augmented reality. 4) Pebelajar dapat menyebutkan macam-macam sel dan organ melalui contoh model 3 dimensi augmented reality. 5) Pebelajar dapat mengidentifikasi macam-macam sel dan organ melalui contoh model 3 dimensi augmented reality. 6) Pebelajar dapat mengelompokkan macam-macam sel dan organ melalui contoh model 3 dimensi augmented reality, 7) Pebelajar dapat membandingkan macam-macam sel dan organ melalui contoh model 3 dimensi augmented reality.

\section{Select Methods, Media, and Materials (Memilih Metode, Media dan Bahan)}

Langkah ketiga dam tahapan ASSURE alah memilih metode, media dan bahan yang dijabarkan dibawah ini

a) Metode yang digunakan pada pembelajaran pada bab organisasi makhluk hidup adalah menggunakan metode observasi agar pebelajar aktif melakukan pengamatan secara individual. Selain itu, metode simulasi untuk mengawali pembelajaran agar memperoleh perhatian pebelajar.

b) Pemilihan Format Media yang digunakan dalam pembelajaran ini yaitu gambar, teks dan suara agar dapat 
mewadahi dari gaya belajar dari masing-masing pebelajar

c) Bahan yang dikembangkan dalam pembelajaran organisasi makhluk hidup ini adalah pengembangan augmented reality menggunakan model 3 dimensi yang dikombinasikan dengan poster sebagai media persuasif. Model 3 dimensi berisikan macammacam bagian dari makhluk hidup. Sementara poster digunakan untuk mengajak pebelajar untuk mengikuti prosedur yang harus diketahui untuk memperoleh informasi dari konkret sehingga membentuk pengetahuan abstrak.

\section{Utilize Media and Materials} (Memanfaatkan Media dan Bahan)

Tahapan selanjutnya adalah pemanfaatan media dan bahan ajar, terdapat beberapa langkah yang dikenal dengan 5P.

a) Preview Materials meninjau bahan ajar yakni pengembangan augmented reality dengan model 3 kombinasi dengan poster yang akan ditinjau oleh ahli baik desain, isi media serta pembelajar akan meninjau materi berupa organisasi makhluk hidup

b) Prepare Materials produk pengembangan berorientasi pada pebelajar atau student centered maka dikembangkan pula buku panduan khusus dalam penerapannya pada proses pembelajaran.

c) Prepare The Environment pembelajaran disiapkan di lingkungan luar kelas dengan menempelkan poster-poster pada objek benda untuk discan menggunakan kamera smartphone yang diinstal aplikasi berteknologi augmented reality

d) Prepare The Learners pebelajar telah diberi apersepsi oleh pembelajar mengenai topik yang akan diajarkan melalu pengembangan produk augmented reality dengan model 3 kombinasi dengan poster, pebelajar diberi motivasi sebelum menggunakan produk ini pada proses pembelajaran, serta dengan produk ini balikan dari pebelajar diharapkan akan muncul.

e) Provide The Learning Experiences hal yang dilakukan pembelajar dalam proses pembelajaran nantinya hanya sebagai fasilitator dan membantu pebelajar apabila kesulitan dalam pemanfaatan produknya.

\section{Require Learner Participation}

Pendekatan yang dilakukan adalah student centered dan teori belajar belajar menggunakan konstruktivistik diharapkan dengan konsep gamification dari pengembangan augmented reality dengan model 3 dimensi setelah menggunakan produk ini diharapkan adanya balikan berupa sebuah kesimpulan dari adanya mencatat melalui lembar pengamatan.

\section{Evaluation And Revise}

a) Evaluasi ini telah dimodifikasi dalam melakukannya. Hal yang dimo-difikasi alah review dari para ahli yang diambil dari model Dick dan Carey. Berpijak pada pendapat Dick, Carey dan Carey (2009) menyatakan bahwa fokus dari evaluasi ini adalah data pengguna, namun tidak kalah penting juga melakukan review dari ahli-ahli. Review ahli-ahli menjadi penting guna memperoleh pendapat dari berbagai pihak mengenai isi/konten menurut ahli bidang studi, stra-tegi pembelajaran sangat cocok atau tidak dari ahli desain pembelajaran, dan desain fisik dari ahli media lain (Suparman, 2012). Untuk itu evaluasi formatif dia-kukan dalam enam tahap yakni evaluasi ahli isi, ahli media, ahli desain, perora-ngan, kelompok kecil, dan kelompok besar.

b) Revisi dilakukan berdasarkan saran dan masukan dari ahli isi, ahli desain, ahli media, uji coba perorangan, uji coba kelompok kecil, dan uji coba kelompok besar. Masukan dan saran dari para ahli segera digunakan untuk merevisi purwa-rupa sebelum 
digunakan pada tahap yang lain (Suparman, 2012). Setelah adanya masukan dan saran dari berbagai ahli maka diujicobakan pada perorangan. Hal ini berkelanjutan sampai tahapan akhir yakni uji coba kelompok besar.

\section{HASIL DAN PEMBAHASAN}

Berdasarkan hasil angket ahli media diperoleh total persentase $\mathbf{9 7 , 9 2 \%}$, hasil angket ahli desain diperoleh total persentase $\mathbf{1 0 0 \%}$, hasil angket ahli materi diperoleh total persentase $\mathbf{9 0 \%}$, dari uji coba perorangan diperoleh skor persentase $\mathbf{7 0 \%}$, uji coba kelompok kecil diperoleh skor persentase $\mathbf{8 2 , 2 \%}$ dan dari uji coba kelompok besar diperoleh skor persentase 77,63\%. Untuk peroleh hasil belajar diperoleh 26 dari 31 siswa memperoleh hasil diatas KKM 75 sementara 5 siswa dibawah KKM. Hal ini menunjukkan bahwa produk pembelajaran organisasi makhluk hidup berbasis gamification menggunakan mobile augmented reality ini dikategorikan sangat, sangat efektif, efisien dan menyenangkan.

\section{KESIMPULAN DAN SARAN}

Kajian yang diperoleh setelah melakukan penelitian terhadap produk didapatlah kelebihan aplikasi mobile augmented reality dan poster berbasis gamification sebagai berikut. 1) Produk ini dapat digunakan untuk pembelajaran secara mandiri/individual. 2) Materi yang disajikan sudah sesuai dengan tujuan dan memenuhi syarat, 3) Alternatif pencapaian tujuan pembelajaran sehingga mampu menyediakan kebutuhan individu pebelajar

Kajian yang diperoleh setelah melakukan penelitian mengenai kelemahan aplikasi mobile augmented reality dan poster berbasis gamification sebagai berikut 1) Pada buku panduan produk terkendali bahasa penyampaian untuk pebelajar, 2) Materi yang disajikan perlu penambahan, 3) Produk ini belum mewadahi kemampuan individu yang berkemampuan auditor karena belum tersedianya suara
Saran untuk produk yang dihasilkan dapat dimanfaatkan secara maksimal dalam kegiatan pembelajaran, maka terdapat beberapa saran dikembangkan, antara lain: 1) Menyediakan sumber daya yang dibutuhkan untuk mengoperasikan media ini yakni smartphone dan poster, 2) Pebelajar untuk kelas 7 SMP, 3) Membaca buku panduan sebelum menggunakan agar mengerti langkah-langkah setiap tahapan baik dalam penginstalan maupun penggunaan, 4) Memahami tujuan pembelajaran, 5) Mencatat hasil yang telah diamati melalui lembar pengamatan.

\section{DAFTAR PUSTAKA}

Joan, R. 2015. Enhancing Education Through Mobile Augmented Reality. Makalah disajikan pada $I$ Managers Journal of Educational Technology. Tamil Nadu.

Lee, J.,J. \& Hammer, J. 2011. Gamification in Education: What, How, Why Bother?. Academic Exchange Quarterly, (online) 15 (2), (https://www.uwstout.edu/soe/pro fdev/resources/upload/LeeHammer-AEQ-2011.pdf)

Molenda, M., \& Boling, E. 2008. Creating. Dalam Michael Molenda dan Al Januszewski (Ed.), Educational Technology A Definition with Commentary (hlm.81-140). New York: Lawrence Erlbaum Associates.

Olsson, M, Mozelius, P \& Collin, J. 2015. Visualitation and Gamification of E-learning and Programming Education. The Electronic Journal of E-learning , (online) 13(6):441454, (www.ejel.org), diakses 10 Oktober 2016 
Sadiman, A.S., Rahardjo, R., Haryono, A., Rahardjito. 2012. Media Pendidikan: Pengertian, Pengembangan, dan Pemanfaatannya. Depok: PT. Rajagrafindo Persada

Smaldino, S.E., Russel, J.D., Heinich, R., Molenda. M. 2004. Instructional Technology and Media for Learning. Ohio: Prentice Hall

Suparman. 2012. Desain Instruksional Modern. Jakarta: Erlangga

Yuliati, L. 2008. Model-Model Pembelajaran Fisika: Teori dan Praktek. Malang:Lembaga Pengembangan Pendidikan dan Pembelajaran (LP3) 